\title{
A rare cause of obstructive defecation in a 29-year-old woman: Ileo-colo-colonic intussusception treated by subtotal colectomy with posterior rectopexy
}

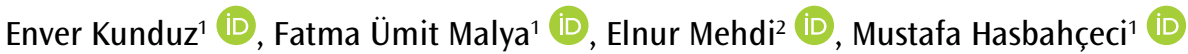

\section{ABSTRACT}

ORCID IDs of the authors: E.K. 0000-0002-7686-2809; F.Ü.M. 0000-0002-6593-6112;

E.M. 0000-0001-6281-1026;

M.H. $0000-0002-5468-5338$

\section{Cite this paper as:}

Kunduz E, Ümit Malya F,

Mehdi E, Hasbahçeci M. A

rare cause of obstructive

defecation in a 29-year-old woman: lleo-colo-colonic

Intussusception treated by subtotal colectomy with posterior rectopexy. Turk J Surg 2018; 34(4):334-336

'Department of General Surgery, Bezmialem Vakif University School of Medicine, İstanbul, Turkey

${ }^{2}$ Department of Radiology, Bezmialem Vakif University School of Medicine, İstanbul, Turkey

Corresponding Author Enver Kunduz e-mail:drkunduz@yahoo.com

Received: 04.10 .2015 Accepted: 17.01.2016 OCopyright 2018 by Turkish Surgical Association
Adult intussusception is a rare clinical condition. In majority of adult cases, there is an underlying cause such as polyps or colon cancers. In the present study, a 29-year-old woman with intermittent and colicky abdominal pain, constipation, and painful defecation, accompanied with distention and sense of rectal fullness, was evaluated with computed tomography. Ileo-colo-colic intussusception was determined. Subtotal colectomy with posterior rectopexy was performed. After the surgery, she was doing well at 13-month follow-up.

Keywords: Obstructive defecation, intussusception, subtotal colectomy

\section{INTRODUCTION}

Intussusception is the invagination of an intestinal segment to the continuing part of the intestine. Usually, it is a pediatric diagnosis due to benign pathologies $(1,2)$. Intussusception as the most common cause of intestinal obstruction occurs most frequently in infants $(3,4)$. However, less than $5 \%$ of the intussusception cases are seen in adults (5). Majority of the cases in children are idiopathic, but an organic cause, such as a polyp or colonic malignancy, is usually detected as the underlying cause of intussusception in adults $(6,7)$. Intussusception in adults most commonly appears as enteroenteric (limited to small intestine). It has been known that colo-colonic intussusception (limited in colon and rectum, without anal protrusion) is the least common type (8). In these circumstances, colonic tumors have been regarded to be the main cause (9). However, intussusception starting from the distal ileal segments to the rectum without proven gastrointestinal malignancy can be a very rare event in adults.

In this paper, we present a young female patient with obstructive defecation caused by ileo-colo-colonic intussusception.

\section{CASE PRESENTATION}

A 29-year-old woman with intermittent and colicky abdominal pain, constipation, and painful defecation, accompanied with distention and a sense of rectal fullness was hospitalized. Similar symptomatology was present for last three months. The patient was described fecal incontinence with a mass protruding from her anus during maximal discomfort. Physical examination revealed distended abdomen with mild tenderness. Patulous anus with a bulky mass protruding through the rectum mimicking prolapse was detected on rectal examination. Coronal curved multiplanar reconstruction of contrastenhanced computed tomography (CT) (Figure 1) showed bowel-within-bowel appearance of ileo-colocolic intussusception elongated from the cecum to the splenic flexure. Surgical intervention had been decided and informed consent had been received. At diagnostic laparoscopy, a dilated and partially invaginated bowel was observed. On conversion to laparotomy, ileo-colo-colic intussusception including terminal ileum and right, transverse, left, and sigmoid colon was determined. Subtotal colectomy had been initiated because all colonic segments invaginated each other down till recto-sigmoidal junction. Subtotal colectomy with ileorectal anastomosis and posterior rectopexy was performed (Figure 2). Pathological examination revealed a benign cecal ulcer causing colo-colic intussusception. After an unremarkable postoperative course, she was doing well at the 13-month follow-up.

\section{DISCUSSION}

Although intussusception is one of the most common leading causes of intestinal obstruction in children, it is very rare in adults $(10,11)$. Enteroenteric intussusception has been reported as the most common type in adults, followed by ileocecal and colo-colonic types. Clinical presentation and the underlying pathology of these patients shows great variability based on these localizations (11). It has been reported that non-specific symptoms including abdominal pain, hematochezia, abdominal mass, and altered bowel habits can be seen in adults (12). In accordance with these findings, intermittent and colicky abdominal pain accompanied with sense of a mass protruding from her anus during maximal discomfort and fecal incontinence was present in our patient. Therefore, it should be kept in mind that 
atypical presentation of intussusception can be seen in adult patients.

A malignant tumor has been reported as the common cause of colo-colonic intussusception in adults; however, benign tumors including lipomas are the main causes of enteroenteric ones. Although it could not be possible to detect a tumor lesion at the cecum and show a photographic and radiological extent of this intussusception down to the anus in the present case, obstructed defecation caused by benign cecal ulceration may be regarded as a rare event. However, a finding of patulous anus with a bulky mass protruding through the rectum should warn physicians to think of such rare pathologies in adult patients.

The extension of intussusception has not been studied in detail in previous studies (11). In the presence of a leading point causing the proximal intestinal segments to be invaginated, it may be thought that the extent of that segment may be directly related with severity of symptoms. Therefore, recurrent partial obstruction with the leading point at the cecum may cause an intussusception from the distal ileal segments down to almost descending colon. In literature, there has been very limited number of cases with ileo-rectal or ileo-anal intusussusception (See comment in PubMed Commons below13-16). A failure in the embryologic development of the mesenteries of the ascending and descending colon to blend with the posterior abdominal wall may be regarded as the underlying cause for such a rare event (11). By that way, it can be possible to see migration of the colon to long distances freely without obstruction. In these cases, limited resection of the intussuscepted segments from the distal ileum to the proximal colon should be performed. However, it could be possible to

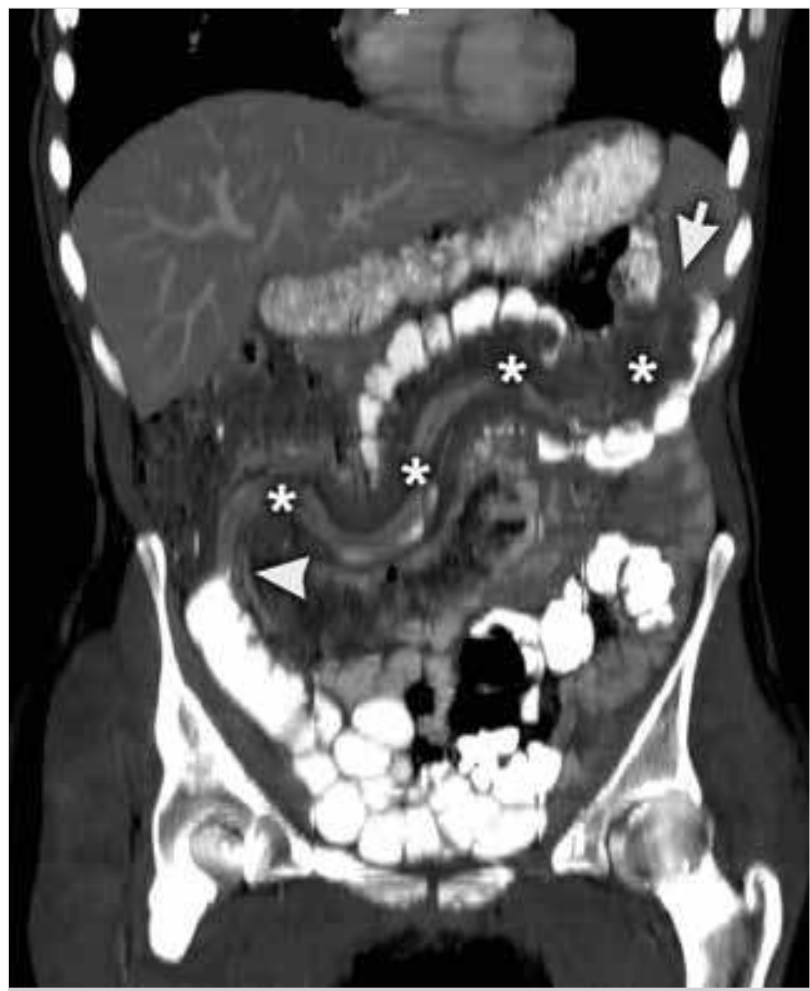

Figure 1. Bowel-within-bowel appearance of colo-colic intussusception (stars) elongating from cecum (arrowhead) to splenic flexure (arrow) resect all intussuscepted segments via subtotal colectomy in the present case. Additionally, suture rectopexy was added to the surgical treatment for the prevention of future prolapse. Therefore, the extent of the pathology in our case might be greater than that in previously reported cases.

Although preoperative diagnosis of intussusception is difficult due to the atypical and non-specific presentation in adults and it is generally determined at laparotomy, it may also be diagnosed by $\mathrm{CT}$, especially in colo-colonic types caused by tumor lesions (17-19). It has been reported that CT is the most sensitive diagnostic test for the confirmation of intussusception with a diagnostic accuracy of 58\%-100\% $(5,20)$. Target or sausage shaped lesions as a concentric hyperdense doublering or bowel-within-bowel appearance are the characteristic signs suggesting intussusception during $\mathrm{CT}$ scan, as in our case. Therefore, early radiological investigation should be conducted for differential diagnosis of intestinal obstruction in adults, even in emergent cases suspicious for intussusception. There have been different approaches for the treatment of intussusception in children (21). Pre- or intraoperative reduction or surgical resection depending on the underlying pathology, which should be confirmed as benign, and on clinical presentation can be performed in these patients. However, laparotomy and bowel resection en-bloc without reduction has been advocated as the management strategy in adults due to the

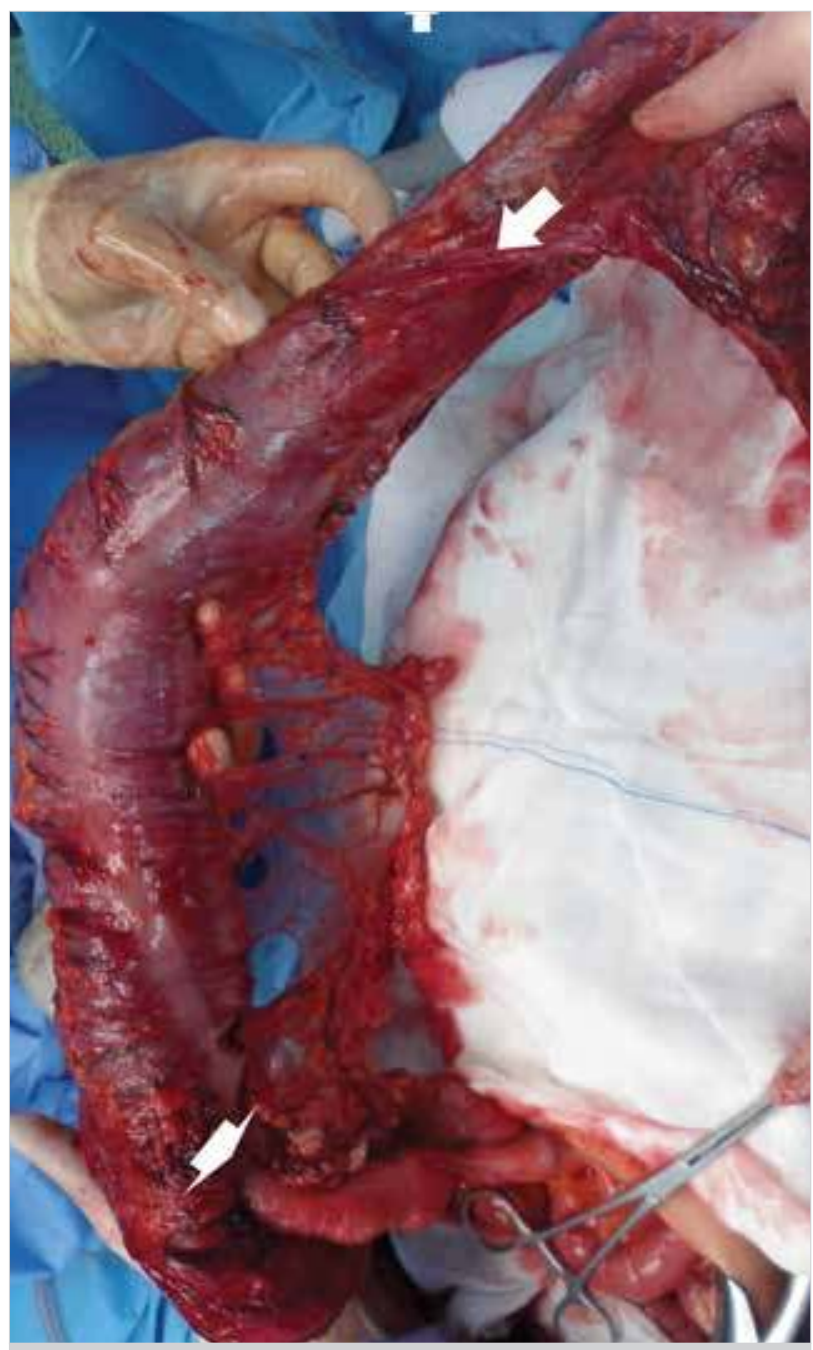

Figure 2. Cecum (arrowhead) to splenic flexure (arrow) 
high rate of malignant causes, although the necessity and extent of the resection in each patient has been controversial (18). Intraoperative reduction has also often been discouraged for the fear of causing tumor rupture and potentially upstaging the cancer $(8,17,22)$.

\section{CONCLUSION}

Although it is a very rare event in adult population, intussusception can be seen in the presence of an underlying pathology including a polyp or malignancy. Enteroenteric small intestinal intussusception is the most common type in adults; however, ileo-colo-colonic intussusception with anal protrusion may occur in the absence of an organic cause. Bowel resection en-bloc without reduction should be offered as the management strategy in adults due to the suspicious malignant causes.

Informed Consent: Written informed consent was obtained from patient who participated in this study.

Peer-review: Externally peer-reviewed.

Author Contributions: Concept - E.K.; Design - E.K., M.H.; Supervision - E.K., M.H.; Resource - E.K. E.M.; Materials - E.K., E.M.; Data Collection and/or Processing - M.H., E.M.; Analysis and/or Interpretation - M.H., F.U.M., E.M.; Literature Search - E.K., F.U.M.; Writing Manuscript - E.K.; Critical Reviews - M.H., F.U.M.

Conflict of Interest: The authors have no conflicts of interest to declare.

Financial Disclosure: The authors declared that this study has received no financial support.

\section{REFERENCES}

1. Huang $B Y$, Warshauer DM. Adult Intusseption: diagnosis and clinical revelance. Radiol Clin North Am 2003; 41: 1137-1151. [CrossRef]

2. Haas EM, Etter EL, Ellis S, Taylor TV. Adult intusseption caused by blunt abdominal trauma. J Trauma 1999; 47: 156-157. [CrossRef]

3. Applegate KE. Intussception in children: evidence-based diagnosis and treatment. Pediatr Radiol 2009; 39 (Suppl 2): S140-143. [CrossRef]

4. Lloyd DA, Kenny SE. The surgical abdomen. In: Walker WA, Goulet O, Kleinman RE, et al. editors. Pediatric Gastrointestinal Disease: Pathopsychology, Diagnosis, Management. $4^{\text {th }}$ ed, BC Decker, Ontario; 2004. p. 604-615.

5. Marinis A, Yiallourou A, Samanides L, Dafnios N, Anastasopoulos $\mathrm{G}$, Vassiliou I, et al. Intussusception of the bowel in adults:a review. World J Gastroenterol 2009; 15: 407-411. [CrossRef]

6. Erkan N, Haciyanli M, Yildirim M, Sayhan H, Vardar E, Polat AF. Intussusception in adults: an unusual and challenging condition for surgeons. Int J Colorectal Dis 2005; 20: 452-456. [CrossRef]
7. Ongom PA, Opio CK, Kijjambu SC. Presentation, aetiology and treatment of adult intussusception in a tertiary Sub-Saharan Hospital: a 10-year retrospective study. BMC Gastroenterology 2014, 14: 86. [CrossRef]

8. H Honjo, M Mike, H Kusanagi, N Kano. Adult Intussusception: A Retrospective Review. World J Surg 2015; 39: 134-138. [CrossRef]

9. Sarr MG, Nagorney DM, Mcllrath DC. Postoperative intussusception in the adult: a previously unrecognized entity? Arch Surg 1981; 116: 114-148. [CrossRef]

10. Kouladouros K, Gärtner D, Münch S, Paul M, Schön MR. Recurrent intussusception as initial manifestation of primary intestinal melanoma: Case report and literature review. World J Gastroenterol 2015; 21: 3114-3120. [CrossRef]

11. Robertson CG, Due SL, Shimokawa K, Yeow M. Caecal tumor biopsy with a rigid sigmoidoscope - Ileorectal intussusception. Int J Surg Case Rep 2015; 12: 1-3. [CrossRef]

12. Barussaud M., Regenet N., Briennon X. Clinical spectrum and surgical approach of adult intussusceptions: a multicentric study. Int J Colorectal Dis 2006; 21: 834-839. [CrossRef]

13. Siddiqui AA, Glynn C, Harford WV, Lopez J. Cecoanal intussusception in an adult caused by cecal polyp. South Med J 2009; 102: 446-447. [CrossRef]

14. Shinoda $M$, Hatano S, Kawakubo H, Kakefuda $T$, Omori T, Ishii S. Adult cecoanal intussusception caused by cecum cancer: report of a case. Surg Today 2007; 37: 802-805. [CrossRef]

15. Redkar RG, Sathe SS, Dalvi AN, Kulkarni BA, Supe AN, Chandrashekhar, et al. lleo-caeco-colic intussusception due to extensive benign lymphoid hyperplasia of the ileo-caecal region (a case report). J Postgrad Med 1991; 37: 177-178.

16. Kuzmich S, Connelly JP, Howlett DC, Kuzmich T, Basit R, Doctor C. lleocolocolic intussusception secondary to a submucosal lipoma: an unusual cause of intermittent abdominal pain in a 62-year-old woman. J Clin Ultrasound. 2010; 38: 48-51.

17. Stewardson RH, Bomberk CT, Nyhus LM. Critical operative management of small bowel obstruction. Ann Surg 1978; 187: 189193. [CrossRef]

18. Mrak K. Uncommon conditions in surgical oncology: acute abdomen caused by ileocolic intussusception. J Gastrointest Oncol. 2014; 5: E75-79.

19. Iko BO, Teal JS, Siram SM, Chinwuba CE, Roux VJ, Scott VF. Computed tomography of adult colonic intussusception: clinical and experimental studies. AJR Am J Roentgenol 1984; 143: 769-772. [CrossRef]

20. Ibrahim D, Patel NP, Gupta M, Fox JC, Lotfipour S. Ileocecal intussusception in the adult population: case series of two patients. West J Emerg Med 2010; 11: 197-200.

21. Pierro A, Donnell SC, Paraskevopoulou C, Carty H, Lloyd DA. Indications for laparotomy after hydrostatic reduction for intussusception. J Pediatr Surg 1993; 28: 1154-1157. [CrossRef]

22. Weilbaecher D, bolin JA, Hearn D, Ogden W 2nd. Intussusception in adults: review of 160 patients. Am J Surg 1971; 121: 531-535. [CrossRef] 